\title{
Toward a more effective approach to stroke: Canadian Best Practice Recommendations for Stroke Care
}

\author{
Patrice Lindsay RN PhD, Mark Bayley MD, Alison McDonald BScPT, Ian D. Graham PhD, \\ Grace Warner PhD, Stephen Phillips MBBS
}

\section{ABSTRACT}

Each year more than 50 ooo Canadians experience a stroke and more than 300000 currently live with its effects. Despite the evidence supporting best practices in stroke care, significant gaps in translating this knowledge into action remains in Canada. An interdisciplinary working group of the Canadian Stroke Strategy was formed to develop best-practice recommendations relevant to Canadian health care. The working group used a rigorous process to develop the guidelines, which included reviewing existing stroke recommendations and research literature, and consulting a national interprofessional consensus panel. The Canadian Best Practice Recommendations for Stroke Care consist of 24 recommendations based on the strongest evidence and address topics that span the full continuum of stroke care. Implementation and dissemination of these recommendations is in progress. Bringing about change will require political will and collaboration throughout the health care system.

Une version française de ce résumé est disponible à l'adresse www.cmaj.ca/cgi/content/full/I78/II/I4I8/DCI

CMAJ 2008;178(II):1418-25

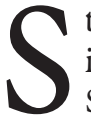
troke is the leading cause of adult neurologic disability in Canada, which costs the Canadian economy at least $\$ 3$ billion annually. ${ }^{1}$ Every year, more than 50000 Canadians experience a stroke and more than 300000 live with the ongoing effects. ${ }^{1,2}$ Over the next Io years, the incidence of stroke is expected to increase with the growing elderly population and with the rising prevalence of diabetes and obesity. ${ }^{3}$ It has been suggested in the literature that integrated and coordinated stroke care, including prevention, acute management, rehabilitation, recovery and reintegration in the community, will save lives. ${ }^{4}$ Canadian projections based on a recently developed economic model for stroke care suggest that, over a 20-year period, organized stroke care, including specialized units and teams and access to acute interventions, could prevent I6o ooo strokes and achieve a projected $\$ 8$ billion in net savings to the Canadian health care system. ${ }^{5}$
A system-wide evaluation of stroke care in the province of Ontario, Canada, revealed significantly improved outcomes following a 6-year period of implementation of an organized stroke care program. ${ }^{6}$ Despite the strength of this evidence, significant gaps in translation of this knowledge into action remain among physicians, nurses, rehabilitation therapists and other health care professionals in Canada. ${ }^{7}$ Data from the Registry of the Canadian Stroke Network, which included information from 2I hospitals in 8 provinces from June 200 I to February 2002, indicated variations in the time from stroke onset to hospital arrival, administration of acute thrombolysis, admission to units specializing in stroke care and use of anticoagulants in patients with atrial fibrillation. ${ }^{7}$ Populationbased chart audits from across Canada ${ }^{8-12}$ indicated considerable variations in stroke care across geographic regions and across hospitals based on their size and designation as a "stroke centre." The 2006 National Stroke Audit in the United Kingdom, the Get With The Guidelines program in the United States and a pilot analysis of stroke indicators in Germany also reported performance differences across sites on several similar stroke indicators. ${ }^{13-15}$

Results of a recent survey about stroke resources conducted by the Canadian Stroke Network ${ }^{16}$ revealed several factors that could account for some of the observed variation in stroke care: the lack of implementation of practice guidelines, infrequent availability of inpatient and ambulatory stroke rehabilitation programs, scarcity of stroke prevention clinics that provide risk-factor management and management of high-risk patients with recent transient ischemic attack or minor stroke, and limited access to computed tomography scanners and therapies such as acute thrombolysis within the therapeutic window for effectiveness. Similarly, results of a survey by Dumoulin and colleagues, ${ }^{17}$ which used

From the Canadian Stroke Network (Lindsay), Ottawa, Ont.; the Ottawa Health Research Institute (Lindsay), Ottawa, Ont.; the Toronto Rehabilitation Institute (Bayley), Toronto, Ont.; the University of Toronto (Bayley, Lindsay), Toronto, Ont.; the Canadian Institutes of Health Research (Graham), Ottawa, Ont.; the Department of Rehabilitation (McDonald), Queen Elizabeth II Health Sciences Centre, Halifax, NS; the Department of Neurology (Phillips), Queen Elizabeth II Health Sciences Centre, Halifax, NS.; and the Department of Occupational Therapy (Warner), Dalhousie University, Halifax, NS 
standardized stroke scenarios to evaluate services provided by I8oo stroke rehabilitation clinicians, revealed important variations in practice choices.

The findings of these audits and surveys demonstrate the need to improve the prevention, treatment and rehabilitation of stroke in Canada. The Canadian Stroke Strategy, a joint initiative of the Canadian Stroke Network and the Heart and Stroke Foundation of Canada, prioritized the development, dissemination and implementation of evidence-based bestpractice recommendations for stroke care as a mechanism for reducing variations in practice and improving stroke care.

Canada needed a single, standardized set of recommendations that would address the full continuum of stroke care, be relevant to the Canadian health care system, synthesize the strongest supporting evidence for best practice in stroke care and provide a clear, prioritized agenda for system improvements throughout the country. Organizations in other countries have published stroke guidelines (see www.strokecenter.org /prof/guidelines.htm). Although, collectively, existing guidelines cover the continuum of stroke care, many guidelines focus on a single component. Not all existing recommendations are relevant to the Canadian health care system; for example, some are models for health care and service delivery specific to a particular country and its available resources. In addition, the target ranges for blood lipid and glucose levels and blood pressure readings are not consistent across existing guidelines.

All guidelines were reviewed using the standardized AGREE (Appraisal of Guidelines Research and Evaluation) instrument. ${ }^{18}$ Findings from this review revealed that the quality of the processes with which existing guidelines were developed and linked to evidence varied among guidelines. For example, most guidelines indicated the strength of the evidence that supported their recommendations. Fewer provided strategies for uptake or addressed health system requirements for, and barriers to, implementation. To our knowledge, no guidelines have attempted to narrow the set of evidence-based recommendations to prioritize the order of implementation. Also, no guidelines have directly addressed performance measurement or processes for evaluating the impact of implementation within their recommendations. Therefore, no one currently published guideline was considered to be comprehensive or user-friendly enough to meet the goals of the Canadian Stroke Strategy.

Endorsement of multiple existing guidelines would potentially overwhelm clinicians and reduce the likelihood of uptake. Therefore, the Canadian Stroke Strategy opted to synthesize existing guidelines into a comprehensive set of recommendations for Canadian health care professionals: the first ever Canadian Best Practice Recommendations for Stroke Care, released in December 2006. ${ }^{19}$

\section{Development of guidelines}

An interdisciplinary working group of the Canadian Stroke Strategy produced the best-practice recommendations through a structured evidence-review and consultation process, in accordance with a validated framework for evaluation and adaptation of practice guidelines..$^{20}$ The composition of the working group is shown in Appendix I, available at
www.cmaj.ca/cgi/content/full/I78/II/I4I8/DC2. The group was divided into 4 task groups to work on specific recommendations. This initiative was informed by 2 previous Canadian studies: the Canadian Stroke Quality of Care Study ${ }^{21}$ and the Stroke Canada Optimization of Rehabilitation through Evidence (SCORE) project. ${ }^{22}$ These studies addressed different components of best practices in stroke care, but they were not comprehensive enough to meet the objectives of the Canadian Stroke Strategy. The working group made an effort to align the stroke recommendations with those of the Canadian Diabetes Association, the Canadian Hypertension Education Program and the Canadian guidelines for the management and treatment of dyslipidemia to ensure that clinicians would receive a single, consistent message regarding the management of patients with these conditions and stroke.

More than 40 relevant guidelines were identified through an extensive literature review. The search strategy identified articles and guidelines published from I990 to 2006 in the following databases: MEDLINE, CINAHL, HealthStar and Evidence-Based Medicine Reviews, which includes Cochrane databases, ACP Journal Club, Database of Abstracts of Reviews of Effects and the Cochrane Controlled Trials Register. Key search terms included "cerebrovascular accident," "stroke," "cerebrovascular disorders," "transient ischemic attack," "subarachnoid hemorrhage," "intracerebral hemorrhage" and "rehabilitation," each used in combination with terms such as "clinical practice guidelines," "care pathways," "systematic reviews," "randomized controlled trials," "observational study," "consensus statement," "position statement" and "policy statement." Manual searches of the tables of contents and reference lists of major peer-reviewed stroke journals, and other relevant articles and journals published from 2003 to 2006 , were also completed. In addition, an Internet search on Google with the search term "stroke guidelines and recommendations" identified sites such as National Guidelines Clearinghouse, Ontario Guidelines Advisory Committee, World Health Organization and the Internet Stroke Centre. Websites of stroke organizations in other countries and regions (e.g., the United Kingdom, Australia, New Zealand, Europe and the United States) were also searched.

Only guidelines with high overall quality ratings, particularly in the "rigour of design" section of the AGREE tool, were considered for adaptation in the development of the Canadian guidelines. Existing guidelines were included in the final set if they were published in English or French within the past Io years, were developed by a group process, were evidence-based, contained clearly defined and specific clinical recommendations and targeted stroke clinicians.

Fourteen sets of guidelines were included in the final review by the 4 interdisciplinary task groups. Group members reviewed each guideline to select, adapt or develop proposed recommendations in their assigned topic area: acute care, rehabilitation, prevention and community care (Table I). All members reached agreement with the final proposed wording of the recommendations, which were further refined and confirmed at a national interdisciplinary consensus conference with 40 panellists (20 task-group members and 20 external participants). At the panel meeting, each recommendation was discussed and input received on final wording. Only I recommendation, on hyperten- 
sion, required more extensive additions and expansion. This work was completed following the consensus panel and finalized among 5 panel members via teleconference. External consultations were held for final input, critique and validation and included 8 key informants and several professional groups. No significant changes were required as a result of these consultations. Stroke survivors and family members participated at all stages of the guideline development process.

The final recommendations met a set of predefined criteria for inclusion. Recommendations were included if they were supported by the highest levels of evidence (e.g., level A or level I, depending on the rating system, which indicates that these are based on evidence from randomized controlled trials or meta-analyses); were considered by the national interdisciplinary consensus panel to be critical for systems change; appeared in more than I published guideline state- ment or reflected strong emerging evidence; collectively represented the full continuum of stroke care; and were relevant to the Canadian health care system.

Experts in performance measurement and analysis within the Canadian Stroke Strategy then developed a core set of performance measures to evaluate the implementation of each recommendation and its impact on patient outcomes. Similar to the recommendations, the performance measures met predefined criteria of having evidence for relevance, validity, opportunity for improvement and feasibility of measurement at a reasonable cost (Appendix 2, available at www.cmaj.ca.cgi /content/full/I78/II/I4I8/DC2). ${ }^{21}$ Detailed measurement equations, including numerators and denominators; cautions about data quality; and information on appropriate data sources were provided in a supplementary manual on performance measurement. This unique feature of providing the

Table 1: Existing guidelines selected for review to develop best-practice recommendations for stroke care in Canada (part 1 of 2 )

\begin{tabular}{|c|c|c|c|c|c|c|c|c|}
\hline \multirow[b]{2}{*}{ Organization } & \multirow[b]{2}{*}{ Guideline } & \multirow[b]{2}{*}{ Stroke type } & \multicolumn{6}{|c|}{ Continuum of care } \\
\hline & & & Prehospital & Emergency & Inpatient & Rehab & Prevention & Community \\
\hline \multirow[t]{4}{*}{$\begin{array}{l}\text { American Stroke } \\
\text { Association }\end{array}$} & $\begin{array}{l}\text { Guidelines for the early management } \\
\text { of patients with ischemic stroke (2003) }\end{array}$ & $\begin{array}{l}\text { Ischemic } \\
\text { stroke (first } \\
24-48 \text { h) }\end{array}$ & $X$ & $X$ & $\begin{array}{c}X \\
(48 h)\end{array}$ & & & \\
\hline & $\begin{array}{l}\text { Guidelines for the early management } \\
\text { of patients with ischemic stroke (2005) }\end{array}$ & $\begin{array}{l}\text { Ischemic } \\
\text { stroke }\end{array}$ & $X$ & $X$ & $\begin{array}{c}X \\
(48 h)\end{array}$ & & & \\
\hline & $\begin{array}{l}\text { Guidelines for prevention of stroke in } \\
\text { patients with ischemic stroke or } \\
\text { transient ischemic attack (2006) }\end{array}$ & $\begin{array}{l}\text { Ischemic } \\
\text { stroke, transi- } \\
\text { ent ischemic } \\
\text { attack }\end{array}$ & & $X$ & $X$ & & $x$ & $X$ \\
\hline & $\begin{array}{l}\text { Management of adult stroke rehabilita- } \\
\text { tion care: a clinical practice guideline } \\
(2005)\end{array}$ & All types & & & & $X$ & & \\
\hline \multirow[t]{2}{*}{$\begin{array}{l}\text { Australian Stroke } \\
\text { Association }\end{array}$} & $\begin{array}{l}\text { Clinical guidelines for acute stroke } \\
\text { management (2003) }\end{array}$ & All types & $X$ & $X$ & $X$ & & & \\
\hline & $\begin{array}{l}\text { Clinical guidelines for stroke } \\
\text { rehabilitation and recovery (2005) }\end{array}$ & All types & & & & $X$ & & $X$ \\
\hline $\begin{array}{l}\text { Canadian Hyper- } \\
\text { tension Education } \\
\text { Program }\end{array}$ & $\begin{array}{l}\text { Canadian Hypertension Education } \\
\text { Program recommendations (2006) }\end{array}$ & All types & & & $X$ & & $x$ & \\
\hline $\begin{array}{l}\text { Canadian } \\
\text { Cardiovascular } \\
\text { Society }\end{array}$ & $\begin{array}{l}\text { Guidelines for the diagnosis and } \\
\text { treatment of dyslipidemia and } \\
\text { prevention of cardiovascular disease } \\
(2006)\end{array}$ & All types & & & & & $x$ & \\
\hline $\begin{array}{l}\text { Canadian Diabetes } \\
\text { Association }\end{array}$ & $\begin{array}{l}\text { Clinical practice guidelines for the } \\
\text { prevention and management of } \\
\text { diabetes in Canada (2003) }\end{array}$ & All types & & & $x$ & & $x$ & \\
\hline \multirow{4}{*}{$\begin{array}{l}\text { Canadian Stroke } \\
\text { Quality of Care } \\
\text { Study }\end{array}$} & $\begin{array}{l}\text { Canadian Stroke Quality of Care Study: } \\
\text { acute care }(2004)\end{array}$ & $\begin{array}{l}\text { Ischemic } \\
\text { stroke }\end{array}$ & $x$ & $X$ & $X$ & & & \\
\hline & $\begin{array}{l}\text { Canadian Stroke Quality of Care Study: } \\
\text { telestroke (2005) }\end{array}$ & All types & & $X$ & & & & \\
\hline & $\begin{array}{l}\text { Canadian Stroke Quality of Care Study: } \\
\text { stroke prevention (2005) }\end{array}$ & All types & & & & & $X$ & \\
\hline & $\begin{array}{l}\text { Canadian Stroke Quality of Care Study: } \\
\text { stroke rehabilitation (2006) }\end{array}$ & All types & & & & $x$ & & \\
\hline $\begin{array}{l}\text { European Stroke } \\
\text { Initiative }\end{array}$ & $\begin{array}{l}\text { Recommendations for stroke } \\
\text { management: update } 2003\end{array}$ & All types & $x$ & $X$ & $X$ & $X$ & $x$ & $x$ \\
\hline $\begin{array}{l}\text { Heart and Stroke } \\
\text { Foundation of } \\
\text { Ontario* }\end{array}$ & $\begin{array}{l}\text { Best practice guidelines for stroke care } \\
(2003)\end{array}$ & All types & $X$ & $X$ & $X$ & $X$ & $x$ & $x$ \\
\hline
\end{tabular}


performance measures directly in the recommendations document made the Canadian guidelines more comprehensive than previously published guidelines. This was considered to be essential because the public and funders increasingly demand accountability within the health care system, and the performance measures support the imperative to be accountable for the quality of health care delivery and improvements.

\section{The recommendations}

The final best-practice guidelines consist of 24 recommendations that are presented in 6 sections: public awareness and responsiveness; patient and family education; prevention of stroke, which focuses on lifestyle management and secondary prevention; acute stroke management; stroke rehabilitation; and follow-up and community reintegration after stroke (Box
I). Box 2 displays the unique format of these recommendations using the example of care in an acute stroke unit.

Recommendations such as patient and family education, and identification and treatment of depression after stroke are relevant to, and should be implemented throughout, the continuum of care by all health care professionals. Those on stroke rehabilitation emphasize the need for early assessment of rehabilitation potential with the use of standardized assessment tools. They then address the critical components of providing inpatient or community-based rehabilitation. The rehabilitation section does not provide detailed recommendations for each functional area affected by stroke because these recommendations are contained in related work by the SCORE project. ${ }^{22}$ To avoid duplication, the Canadian stroke recommendations include links to the SCORE project and endorsement of that work.

Table 1: Existing guidelines selected for review to develop best-practice recommendations for stroke care in Canada (part 2 of 2 )

\begin{tabular}{|c|c|c|c|c|c|c|c|c|}
\hline \multirow[b]{2}{*}{ Organization } & \multirow[b]{2}{*}{ Guideline } & \multirow[b]{2}{*}{ Stroke type } & \multicolumn{6}{|c|}{ Continuum of care } \\
\hline & & & Prehospital & Emergency & Inpatient & Rehab & Prevention & Community \\
\hline $\begin{array}{l}\text { Royal College of } \\
\text { Physicians } †\end{array}$ & $\begin{array}{l}\text { National clinical guidelines for stroke, } \\
\text { second edition (2004) }\end{array}$ & All types & $x$ & $x$ & $x$ & $x$ & $x$ & $x$ \\
\hline \multirow[t]{3}{*}{$\begin{array}{l}\text { Scottish } \\
\text { Intercollegiate } \\
\text { Guidelines } \\
\text { Network }\end{array}$} & $\begin{array}{l}\text { Management of patients with stroke } \\
\text { part I: assessment, investigation, } \\
\text { immediate management and secondary } \\
\text { prevention, no. } 13 \text { (1997) }\end{array}$ & All types & $x$ & $x$ & $x$ & & $x$ & \\
\hline & $\begin{array}{l}\text { Management of patients with } \\
\text { stroke part III: identification and } \\
\text { management of dysphagia, no. } 78 \\
\text { (2004) }\end{array}$ & $\begin{array}{l}\text { All types with } \\
\text { confirmed } \\
\text { dysphagia }\end{array}$ & & $x$ & & $\mathrm{X}$ & & $\mathrm{x}$ \\
\hline & $\begin{array}{l}\text { Management of patients with } \\
\text { stroke part IV: rehabilitation, } \\
\text { prevention and management of } \\
\text { complications, and discharge } \\
\text { planning, no. } 64 \text { (2005) }\end{array}$ & All types & & & $x$ & $x$ & & $x$ \\
\hline $\begin{array}{l}\text { New Zealand } \\
\text { Stroke Foundation }\end{array}$ & $\begin{array}{l}\text { Life after stroke: New Zealand } \\
\text { guideline for management of stroke } \\
\text { best practice evidence-based } \\
\text { guideline (2003) }\end{array}$ & $\begin{array}{l}\text { Ischemic } \\
\text { stroke, transi- } \\
\text { ent ischemic } \\
\text { attack }\end{array}$ & $x$ & $x$ & $x$ & $\mathrm{x}$ & $x$ & $x$ \\
\hline
\end{tabular}




\section{Dissemination and implementation}

The Canadian Best Practice Recommendations for Stroke Care advocate a coordinated and integrated approach to stroke prevention, treatment, rehabilitation and recovery in the community. The dissemination of these recommendations is a critical component of a multifaceted approach to reaching this goal. Dissemination activities include provincial and local consultations with front-line clinicians and political decision-makers to discuss the recommendations as well as the challenges and successes realized during implementation. Teaching materials, learning modules and point-of-care tools are also being developed to support implementation of the recommendations in different clinical settings.

The Canadian recommendations uniquely include sections outlining the implications for the health care system as well as specific performance measures for each recommendation (Box 2). The system implications describe the key resources and processes that are required for effective implementation of the recommendations. These key enablers require dialogue and action by health system policy leaders and managers in collaboration with clinicians. The set of performance measures is provided to enable clinicians, policy-makers and managers to measure and monitor the impact of implementing the recommendations using a consistent and standardized approach, and to determine baseline performance levels and changes in performance related to the delivery of stroke care over time. Audit tools that contain all required elements to calculate each performance measure are currently being finalized. The results of early data collection are already being

\section{Box 1: Canadian Best Practice Recommendations for Stroke Care* (part 1 of 2)}

\section{Section 1: public awareness}

1. Public awareness: All persons (members of the public) should be able to recognize and identify at least 2 signs and symptoms of stroke (sudden weakness, sudden trouble speaking, sudden vision problems, sudden headache, sudden dizziness) and know to take appropriate action (seek immediate medical attention) (evidence level III).

Section 2: patient and family

2. Patient and caregiver education: Information and education should be provided for all patients with stroke and their families and caregivers at all stages of care across the continuum (prevention, acute care, rehabilitation, community reintegration) (evidence level A). Information and education should be interactive, timely, up to date, provided in a variety of languages and formats (evidence levels $A / B$ ).

\section{Section 3: prevention of stroke}

3. Lifestyle management: Persons at risk of stroke and patients who have had a stroke should be assessed for and given information about risk factors, lifestyle management issues (exercise, smoking, diet, weight, alcohol, stress management) and be counselled about possible strategies to modify their lifestyle and risk factors (evidence levels $B / C$ ).

4. Blood pressure assessment: All persons at risk of stroke should have their blood pressure measured at each health care encounter (evidence level C). Patients found to have elevated blood pressure should undergo thorough assessment for the diagnosis of hypertension following the current guidelines of the Canadian Hypertension Education Program (evidence level A). Blood pressure management: Patients with ischemic stroke who are beyond the hyperacute period should be prescribed antihypertensive treatment to target normal blood pressure (evidence level A).

5. Lipid assessment: Fasting lipid levels (total cholesterol, triglycerides, low-density lipoprotein [LDL] cholesterol and high-density lipoprotein [HDL] cholesterol) should be measured every 1-3 years and other cardiovascular risk factors assessed for all men 40 years or older, and women who are postmenopausal and/or 50 years or older (evidence level C).

Lipid management: Ischemic stroke patients with LDL cholesterol $>2.0 \mathrm{mmol} / \mathrm{L}$ should be managed with lifestyle modification, dietary guidelines and medication recommendations (evidence level A).

6. Diabetes assessment: All individuals should be evaluated annually for type 2 diabetes risk on the basis of demographic and clinical criteria (evidence level D).

Diabetes management: Glycemic targets must be individualized (evidence level III); however, therapy in most patients with type 1 or type 2 diabetes should be targeted to achieve a hemoglobin $\mathrm{A}_{1 \mathrm{c}}$ concentration $\leq 7.0 \%$ in order to reduce the risk of microvascular complications (evidence level A).

7. Antiplatelet therapy: All patients with ischemic stroke or transient ischemic attack should be on antiplatelet therapy for secondary prevention of recurrent stroke unless there is an indication for anticoagulation or a contraindication to acetylsalicylic acid (ASA) (evidence level A).

8. Anticoagulation in atrial fibrillation patients: For primary prevention of stroke in patients with atrial fibrillation, ASA or anticoagulation with warfarin should be considered based on the clinical circumstances (evidence level A).

9. Carotid intervention: Patients with symptomatic carotid artery disease of 70\%-99\% stenosis (measured by angiography or by 2 concordant noninvasive imaging modalities) should be offered carotid intervention (carotid endarterectomy) within 2 weeks of the incident stroke or transient ischemic attack (evidence level A).

Section 4: acute stroke management

10. Acute stroke unit care: Patients admitted to hospital because of an acute stroke should be treated in an interdisciplinary stroke unit (evidence level A).

11. Brain imaging: All patients with suspected acute stroke should undergo brain imaging immediately (evidence level B). 
used to demonstrate to funders the value of coordinated stroke care. These results are also being used locally and within regions to guide quality-improvement activities, such as improved access to computed tomography immediately upon arrival in the emergency department, development of specialized stroke units and demonstration of the need for rehabilitation assessments. This standardization of measurement facilitates ongoing activities to establish benchmarks and targets for stroke care performance within Canada.

The reorganization and standardization of services poses considerable challenges, particularly in rural areas. For example, results of a survey conducted across Canada in 2006 by the Canadian Stroke Network ${ }^{16}$ ( $n=173 ; 35 \%$ response rate) indicated that most stroke care in Canada was provided by internal medicine specialists and primary care physicians, both in hospital and in the community. A minority ( $4 \mathrm{r} \%$ ) of small and rural hospitals had implemented clinical practice guidelines for stroke care, compared with $63 \%$ of larger community-based hospitals and $8 \mathrm{I} \%$ of teaching hospitals. ${ }^{16,23}$ A similar survey (unpublished data) of acute care hospitals ( $n=102 ; 93 \%$ response rate) in the predominantly rural provinces of New Brunswick, Newfoundland and Labrador, Nova Scotia and Prince Edward Island in 2004-2005, using an instrument adapted from one used to conduct a similar survey in Ontario in $1999 .{ }^{24}$ They found that $8 \mathrm{r} \%$ of emergency departments did not provide thrombolytic therapy and that $77 \%$ of hospitals did not have a formal protocol for managing stroke patients. Once admitted, $89 \%$ of stroke patients received care in general medical wards and only $19 \%$ of hospitals provided coordinated interdisciplinary care.

\section{Box 1: Canadian Best Practice Recommendations for Stroke Care* (part 2 of 2)}

\section{Section 4: acute stroke management (continued)}

12. Blood glucose: All patients with suspected acute stroke should have their blood glucose concentration checked immediately. Blood glucose measurement should be repeated if the first value is abnormal or if the patient is known to have diabetes (evidence levels B/C).

13. Acute thrombolytic therapy: All acute ischemic stroke patients should be evaluated to determine their eligibility for treatment with intravenous tissue-plasminogen activator using the criteria from the National Institute of Neurological Disorders and Stroke rt-PA Stroke Study. Administration of tissue-plasminogen activator should follow the American Stroke Association guidelines (evidence levels A/B).

14. Carotid artery imaging: Carotid artery imaging should be performed within 24 hours of a carotid territory transient ischemic attack or nondisabling ischemic stroke unless the patient is clearly not a candidate for carotid endarterectomy (evidence level B).

15. Dysphagia assessment: All patients with stroke should have their swallow screened prior to initiating oral intake of fluids or food using a simple valid reliable bedside testing protocol (evidence level B). Patients with stroke presenting with features indicating dysphagia or pulmonary aspiration should receive a full clinical assessment of swallowing by a speech-language pathologist or appropriately trained specialist who should advise on safe swallow and consistency of diet and fluids (evidence level A).

16. Acute ASA therapy: After brain imaging has excluded intracranial hemorrhages, all acute stroke patients should be given at least $160 \mathrm{mg}$ of ASA immediately as a one-time loading dose (evidence level A).

17. Management of subarachnoid and intracerebral hemorrhage: Patients with suspected subarachnoid hemorrhage should have an urgent neurosurgical consultation for diagnosis and treatment. Patients with cerebellar hemorrhage should have an urgent neurosurgical consultation for consideration of craniotomy and evacuation of the hemorrhage. Patients with supratentorial intracerebral hemorrhage should be cared for in a stroke unit (evidence levels B/C).

\section{Section 5: stroke rehabilitation}

18. Initial stroke rehabilitation assessment: All people admitted to hospital with acute stroke should have an initial assessment by rehabilitation professionals as soon as possible after admission. All people with acute stroke not admitted to hospital should undergo a comprehensive outpatient assessment, which includes a medical evaluation and functional assessments (evidence level C).

19. Provision of inpatient rehabilitation: All patients with stroke who are admitted to hospital and who require rehabilitation should be treated in a comprehensive or rehabilitation stroke unit by an interdisciplinary team (evidence level A).

20. Components of inpatient stroke rehabilitation: All patients with stroke should begin rehabilitation therapy as early as possible once medical stability is reached (evidence level 1 ).

21. Identification and management of post-stroke depression: All patients with stroke should be considered to be at a high level of risk for depression. The clinical team should assess the patient's prior history of depression and previous risk factors of depression as part of the initial screening. All patients with stroke should be screened for depression initially and at 3-month intervals or key stages of the rehabilitation process and after rehabilitation services have been discontinued (evidence level A).

22. Shoulder pain assessment and treatment: Factors that contribute to, or exacerbate, shoulder pain should be identified and managed appropriately. Joint protection strategies should be instituted to minimize joint trauma (evidence level A).

23. Community-based rehabilitation: Stroke survivors should continue to have access to specialized stroke care and rehabilitation after leaving hospital (acute and/or inpatient rehabilitation) (evidence level A).

Section 6: follow-up and community reintegration

24. Follow-up and evaluation in the community: Stroke survivors and their caregivers should have their individual psychosocial and support needs reviewed on a regular basis. Any stroke survivor with reduced activity at 6 months or later after stroke should be assessed for appropriate targeted rehabilitation (evidence level A).

*This list is a summary of the recommendations. For full text, please visit www.canadianstrokestrategy.ca 
Data from an extensive evaluation of the Ontario stroke system highlights the need for system-wide implementation strategies. ${ }^{6}$ These strategies may include restricting the number of hospitals providing stroke care to achieve "critical mass" in those that do, professional education programs to increase human resources, the use of telemedicine technology and the development of point-of-care reminders and tools to support clinical practice. Ongoing audits of performance and provision of feedback directly to service providers may also promote implementation and inform the ongoing effort to minimize regional disparities in the delivery of stroke care in Canada.
Since the release of the Canadian stroke care recommendations in 2006, many individual provincial stroke strategies have adopted these recommendations, identified priority areas for implementation and developed educational resources to support implementation. Many local health care facilities already had some of the recommendations in place, including the establishment of stroke units, rapid access to computed tomography and standing orders for antiplatelet therapy. These facilities have used the stroke recommendations as an opportunity to expand the scope of stroke practices. Other facilities have used the recommendations as a starting point to develop protocols for acute thrombolysis in their emergency

\section{Box 2: Recommendation no. 10: stroke unit care (direct excerpt from Canadian Best Practice Recommendations for} Stroke Care)*

Patients admitted to hospital because of an acute stroke should be treated in an interdisciplinary stroke unit (Canadian Stroke Quality of Care Study, Stroke Canada Optimization of Rehabilitation through Evidence [SCORE] project, Scottish Intercollegiate Guidelines Network no. 64; evidence levels A/I).

- A stroke unit is a specialized, geographically defined hospital unit dedicated to the management of stroke patients (Australian Stroke Association, Royal College of Physicians; evidence levels A/I).

- The core interdisciplinary team should consist of appropriate levels of medical, nursing, nutrition, occupational therapy, physiotherapy, social work and speech-language pathology staff. Additional disciplines may include pharmacy, (neuro)psychology and recreation therapy (Scottish Intercollegiate Guidelines Network no. 64, Australian Stroke Association, Stroke Canada Optimization of Rehabilitation through Evidence [SCORE] project; evidence level B).

- The interdisciplinary team should assess patients within 48 hours of admission and formulate a management plan (Canadian Stroke Strategy Best Practices and Standards; evidence level C).

- Clinicians should use standardized, valid assessments to evaluate the patient's stroke-related impairments and functional status (Royal College of Physicians, Canadian Stroke Strategy Best Practices and Standards; evidence level III).

\section{Rationale}

Level 1 evidence from a systematic review of randomized controlled clinical trials indicates that stroke unit care reduces the likelihood of death and disability in men and women of any age with mild, moderate or severe stroke. Stroke unit care is characterized by a coordinated interdisciplinary team approach for preventing stroke complications, preventing stroke recurrence, accelerating mobilization, and providing early rehabilitation therapy.

Note: Refer to recommendation no. 20 for components of inpatient stroke rehabilitation (which commences in the acute care hospital) and for additional information on stroke unit usage for inpatient rehabilitation.

System implications

- Organized system of stroke care, including stroke units with a critical mass of trained staff, and interdisciplinary team. If not feasible, then mechanisms for coordinating the care of stroke patients to ensure application of best practices and optimization of outcome.

- Definition, dissemination and implementation of best practices for stroke patients across the continuum of care.

- Mechanisms for ongoing monitoring and evaluation, with a feedback loop for interpretation of findings and opportunities for quality improvement.

\section{Performance measures}

- Number of stroke patients treated on a stroke unit at any time during their inpatient hospital stay for an acute stroke event (numerator) as a percentage of total number of stroke patients admitted to hospital.

- Proportion of total time in hospital for an acute stroke event spent in a stroke unit.

- Percentage increase in telehealth/telestroke coverage to remote communities to support organized stroke care across the continuum of care.

- Percentage of patients discharged to their homes or places of residence following an inpatient admission for stroke.

\section{Measurement notes}

- The first measure of this recommendation could be calculated for all cases, then stratified by type of stroke.

- Definition of stroke unit varies widely from institution to institution. Where stroke units that meet the criteria defined in the recommendation do not exist, then a hierarchy of other stroke care models could be considered: a) dedicated stroke unit, (b) designated area within a general nursing unit where clustering of stroke patients occurs, (c) peripatetic (mobile) stroke team care, (d) managed care in a general nursing unit by staff using guidelines and protocols.

- It is important to note the operational definition of stroke unit being used by any institution collecting these data to ensure standardization and validity when data are collected and reported across institutions.

*See www.canadianstrokenetwork.ca for the complete summary of evidence for this recommendation. 
departments and increase access to rehabilitation therapists during acute care and after discharge. Evaluations of the impact of implementation strategies are under development because only a few provinces had processes to conduct systematic monitoring of performance in place before this year.

To ensure the validity and applicability of the Canadian recommendations for stroke, they will be updated on a 2-year cycle. Additional recommendation topics have been identified based on newer research and feedback from the first iteration and will be included in the next update, which is expected in the fall of 2008. These topics include management of minor stroke and acute transient ischemic attack, cognitive impairment in stroke, prehospital systems for stroke and components of acute inpatient care. Opportunities are also emerging to collaborate with developers of stroke guidelines in organizations globally to consolidate guideline efforts and increase standardization of stroke management across geographic boundaries.

\section{Conclusion}

Improved access to consistent and standardized stroke care, regardless of where in Canada a stroke occurs, is urgently needed. The Canadian recommendations have substantial implications for clinicians, managers and policy-makers alike. As the burden of stroke on the health care system and the broader social community continues to increase with changing population demographics, a shift in the way stroke care is delivered toward better integrated and coordinated systems of care becomes imperative. Bringing about change will require effort at multiple levels in the health care system. Economic modelling, and experience in the United States and Ontario, indicate that adherence to best-practice recommendations will reduce stroke mortality and morbidity and save money. ${ }^{24}$ However, the challenge will be to identify and overcome barriers to applying the recommendations. Bringing about change will require political will and collaboration throughout the health care system.

This article has been peer reviewed.

Competing interests: None declared.

Contributors: Patrice Lindsay is the principal author and is the project leader for the Canadian Stroke Strategy Best Practices and Standards working group as well as the Information and Evaluation working group. She was the primary project leader and editor of the best practices document and conducted much of the background research and reviews. Mark Bayley contributed significantly to the development of the guidelines and this manuscript as the Principal Investigator of the Stroke Canada Optimization of Rehabilitation through Evidence (SCORE) project. Alison McDonald is the co-chair of the Canadian Stroke Strategy Best Practices and Standards working group and is responsible for guiding the development process. She actively contributed to the editing of the recommendations and this manuscript. Grace Warner is a member of the Information and Evaluation working group and contributed information to this manuscript related to the Atlantic Canada Stroke Resource Survey and the development of the performance measures that accompany the recommendations. Stephen Phillips is the senior author and contributed substantially to the writing and formatting of this manuscript. $\mathrm{He}$ is also the co-chair of the Canadian Stroke Strategy Best Practices and Standards working group. He played a major leadership role throughout the guideline development process.

\section{REFERENCES}

I. Moore R, Nao Y, Zhang J, et al. Economic burden of illness in Canada, I993. Ottawa: Environmental Risk Assessment and Case Surveillance Division, Laboratory for Disease Control; I997.

2. Heart and Stroke Foundation of Canada. The growing burden of heart disease and stroke in Canada 2003. Ottawa: The Foundation; 2003. Available: www.cvdinfobase ca/cvdbook/CVD_Eno3.pdf (accessed 2008 Mar io).

3. Katzmarzyk PT. The Canadian obesity epidemic, I985-I998. CMAJ 2002;166:I039-40.

4. Schwamm LH, Pancioli A, Acker JE, et al. Recommendations for the establishment of stroke systems of care: recommendations from the American Stroke Association's Task Force on the Development of Stroke Systems. Stroke 2005;36:690-703.

5. Sharma M. Billions of dollars, tens of thousands of lives at stake - Why aren't proven stroke solutions being used consistently in Canada? [media release] Canadian Stroke Network; 2006 June I4. Available: www.canadianstrokestrategy.ca/eng /whatsnew/news\%2oreleases/juner4_2006_en.pdf (accessed 2008 Apr I8).

6. Lindsay MP, Ladak N; Ontario Stroke Evaluation Advisory Committee. Integrated stroke care in Ontario: stroke evaluation report 2006. Ottawa: Canadian Stroke Network; 2007. Available: www.canadianstrokestrategy.ca/eng/resourcestools /documents/Ontario\%20Stroke\%20Evaluation\%20Report\%202006.pdf (accessed 2008 Apr I8).

7. Kapral MK, Silver FL, Richards J, et al. Registry of the Canadian Stroke Network progress report 200I-2005. Toronto: Institute for Clinical Evaluative Sciences; 2005. Available: www.ices.on.ca/file/RCSN_TechnicalReport_final.pdf (accessed 2008 Mar Io).

8. Kapral MK, Lindsay MP, Silver FL, et al. Registry of the Canadian Stroke Network. Report on the 2002/03 Ontario Stroke Audit. Toronto: Institute for Clinical Evaluative Sciences; 2006.

9. Riopelle RJ, Howse DC, Bolton C, et al. Regional access to acute ischemic stroke intervention. Stroke 200I;32:652-5.

Io. Lewis M, Trypuc J, Lindsay P, et al. Has Ontario's stroke system really made a difference? Healthc Q 2006;9:50-9.

II. Kapral MK, Laupacis A, Phillips SJ, et al; investigators of the Registry of the Canadian Stroke Network. Stroke care delivery in institutions participating in the Registry of the Canadian Stroke Network. Stroke 2004;35:1756-62.

I2. Field TS, Green TL, Roy K, et al. Trends in stroke occurrence in Calgary. Can J Neurol Sci 2004;31:387-93.

I3. Hudson J, Ross C, Taylor K. Joining forces to deliver improved stroke care. Victoria (UK): National Audit Office; 2007.

I4. Heuschmann PU, Biegler MK, Busse O, et al. Development and implementation of evidence-based indicators for measuring quality of acute stroke care: the Quality Indicator Board of the German Stroke Registers Study Group (ADSR). Stroke 2006;37:2573-8.

I5. Lewis et al. The AHA/ASA Get with the Guidelines - Stroke Program is associated with improved use of warfarin in patients with current atrial fibrillation and stroke [abstract]. Stroke 2007;38(Suppl):480.

I6. Canadian Stroke Network. Stroke services and resources inventory: a national survey initiative. Ottawa: the Network; June 2007. Available: www.canadianstrokestrategy .ca/eng/resourcestools/documents/CSN_SSRI\%20Report\%20June\%202007.pdf (accessed 2008 Apr 18).

17. Dumoulin C, Korner-Bitensky N, Tannenbaum C. Urinary incontinence after stroke: identification, assessment, and intervention by rehabilitation professionals in Canada. Stroke 2007:38:2745-5I

I8. AGREE Collaboration Writing Group; Cluzeau FA, Burgers JS, Brouwers M, et al. Development and validation of an international appraisal instrument for assessing the quality of clinical practice guidelines: the AGREE project. Qual Saf Health Care 2003;12:18-23

I9. Canadian Stroke Strategy. Canadian best practice recommendations for stroke care. Ottawa: Canadian Stroke Strategy; 2006. Available: www.canadianstrokestrategy.ca/eng/resourcestools/documents/StrokeStrategyManual.pdf (accessed 2008 Mar Io).

20. Graham ID, Harrison MB, Lorimer $\mathrm{K}$, et al. Adapting national and international leg ulcer practice guidelines for local use: the Ontario leg ulcer community care protocol. Adv Skin Wound Care 2005;18:307-18.

2I. Lindsay MP, Kapral MK, Gladstone D, et al. The Canadian Stroke Quality of Care Study: establishing indicators for optimal acute stroke care. CMAJ 2005;172:363-5.

22. Hurdowar A, Graham ID, Bayley M, et al. Quality of stroke rehabilitation clinical practice guidelines. J Eval Clin Pract 2007;13:657-64.

23. Schwamm LH, Pancioli A, Acker JE, et al. Recommendations for the establishment of stroke systems of care. AHA Scientific Statement. Stroke 2005;36:690-703

24. Tu JV, Porter J. Stroke care in Ontario: hospital survey results. Toronto: Institute for Clinical Evaluative Sciences; 1999.

Correspondence to: Dr. Patrice Lindsay, Canadian Stroke Network, 45I Smyth Rd., Rm. 3105, Ottawa ON KIH 8M5; fax 416 62I-9952; patty@canadianstrokenetwork.ca 